\title{
Hifalomicose em Mustelus schmitti (Springer) (Chondrichthyes, Triakidae)
}

\author{
Manoel Mateus Bueno Gonzalez ${ }^{1,2}$
}

\begin{abstract}
Hyphalomycosis in Mustelus schmitii (Springer) (Chondrichthyes, Triakidae). Both fungal and algal infections have been reported in elasmobranchs. This study describes the first record of hyphalomycosis infection in Mustelus schmitii (Springer, 1940). The data was obtained through the examination of one animal in captivity and ninety five in their natural environment. Was also detected four cases of Fusarium solani infection. The impact of these diseases on the wild population is unknown.

KEY WORDS. Hyphalomycosis, Elasmobranchs, Mustelus schmitti, Brazil
\end{abstract}

Infecções causadas por fungos, algas (Tab. I) e parasitas em elasmobrânquios, têm sido descritas há alguns anos (MCLAUGHLIN \& ZAHL 1966; WILLIAMS 1982; Leibovitz \& Leibovitz 1985a; RipPon 1988; VioletTA et al. 1989). O impacto destas doenças em populações naturais é desconhecido, sendo que as maiores informações foram adquiridas através de espécies mantidas em cativeiro (MUHVICH et al. 1989; VioletTA et al. 1989).

A dificuldade de adquirir informações sobre patologias e parasitas provenientes de populações de elasmobrânquios em seu ambiente natural, está relacionada com o pequeno esforço de coleta para fins de estudos parasitários, quando relacionado à grande quantidade de elasmobrânquios capturados por ano (LEIBOVITZ \& LEIBOVITZ 1985a; STOSKOPF 1993).

Objetivando descrever e adquirir maiores informações sobre infecções por fungos em tubarões, utilizaram-se espécimes de Mustelus schmitti (Springer 1940), vulgarmente chamado de cação-sebastião, provindas da pesca realizada no litoral de Santos, São Paulo. Esta espécie é de fácil obtenção na costa sudeste brasileira, de acordo com FigUEIREDo (1977) e COMPAGNO (1984).

A espécie estudada (Fig. 1), atinge comprimento total de no máximo 1,20 m (Compagno 1984). Pode ser capturada em águas costeiras, com até $30 \mathrm{~m}$ de profundidade (FIGUEIREDO 1977; MICHAEL 1993).

\section{MATERIAL E MÉTODOS}

Durante o período compreendido entre março de 1996 e maio de 1997, foram analisados 95 indivíduos e diagnosticados quatro casos de hifalomicose em caçãosebastião, provenientes de capturas feitas por duas embarcações de pesca artesanal do litoral de Santos, Estado de São Paulo.

1) Núcleo de Pesquisa e Estudo em Chondrichthyes. Avenida Conselheiro Nébias 340 , 11015-002 Santos, São Paulo, Brasil.

2) Departamento de Medicina Veterinária, Universidade Monte Serrat. Avenida Rangel Pestana 99, 11100-000 Santos, São Paulo, Brasil. 
Tab. I. Doenças causadas por fungos e algas em elasmobrânquios.

\begin{tabular}{lll}
\hline \multicolumn{1}{c}{ Doença } & \multicolumn{1}{c}{ Organismo } & \multicolumn{1}{c}{ Elasmobrânquio } \\
\hline Hifalomicose & Fusarium solani & Tubarão-martelo \\
Aureobasidiomicose pelágica & Aureobasidium spp. & Raia \\
Dermatite algal & Chrysophycophyta spp. & Tubarão-cachorro \\
\hline
\end{tabular}

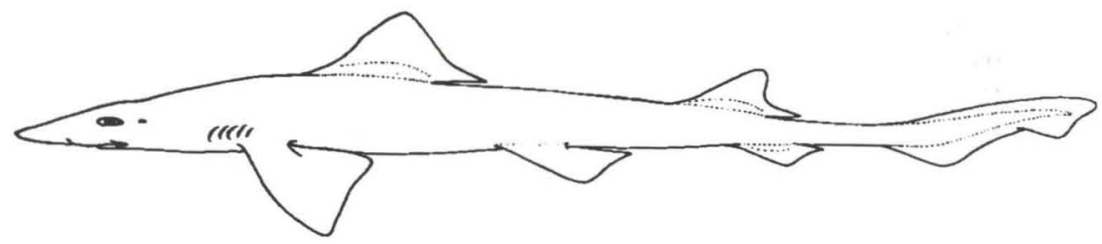

Fig. 1. Mustelus schmitti, vista lateral. Modificado de Compagno (1984).

Somente os tubarões vivos (nos casos analisados, os indivíduos já estavam muito debilitados) foram acondicionados em caixas plásticas com um terço de água com benzocaína, e transportados aos laboratórios do Núcleo de Pesquisa e Estudo em Chondrichthyes, para a realização dos exames parasitológicos.

O procedimento básico para a análise parasitológica, consistiu na raspagem da região do focinho infeccionada, posteriormente o material coletado de lesões foi semeado em meios de cultura de Sabouraud e ágar sangue e mantidos à temperatura média de $30^{\circ} \mathrm{C}$, por um período de 24 a 72 horas.

Para a análise microscópica, foram removidos da cultura com uma agulha, fragmentos do crescimento miceliano, o qual foi colocado em uma lâmina de microscopia com uma gota de azul-algodão de lactofenol. Em algumas amostras, foi difícil a identificação e diagnóstico, devido ao rompimento da estrutura durante a remoção e preparação.

Um exemplar de cação-sebastião foi capturado em boas condições, apenas com pequenas ulcerações na região da cabeça. O tubarão foi mantido em cativeiro de sistema fechado para o acompanhamento do desenvolvimento da patologia, de acordo com procedimento descrito por GONZALEZ (1995).

Segundo Cheung \& Nigrelli (1983), SchäPERCLaus (1992) e EiraS (1994), realizou-se um trabalho intensivo na procura de parasitas internos, que poderiam debilitar o organismo do animal, auxiliando no desenvolvimento de infecções secundárias.

\section{RESULTADOS}

\section{Observações Microscópicas}

Através de exames microscópicos, constatou-se a infecção pelo fungo $\mathrm{Fu}$ sarium solani, na região anterior do focinho. 


\section{Diagnose}

A hifalomicose é caracterizada por necrose muscular, com penetração hifal na cartilagem. As fusárias são caracterizadas por suas conídias multicelulares, fusiformes, ou em forma de foice e por conidióforos dispostos como os raios de uma roda sobre ramos curtos de hifa (MOORE-LANDERCKER 1972). Os microconidióforos de $F$. solani são alongados e a macroconídia é assimetricamente septada na parte distal (Fig. 2).

Quatro indivíduos analisados apresentavam necrose na região do focinho, sendo possível em dois casos, a visualização do condrocrânio (Fig. 3). Associado à esta necrose, pôde-se observar a presença de ulcerações que variavam de 0,1 a 0,5 $\mathrm{cm}$ de diâmetro, por toda a região ventral. Estas ulcerações apresentavam-se com coloração levemente esverdeada. No estágio final, ocorreu a perda total da região do focinho, estando associado à esta, grandes hemorragias que contribuíram para a morte dos tubarões.

Não foram encontrados outros parasitas potenciais, que poderiam causar debilitação e possível morte dos elasmobrânquios estudados.

\section{Observações em Cativeiro}

O exemplar capturado para as observações em cativeiro possuía pequenas ulcerações na região da cabeça. Durante a primeira semana o tubarão não apresentou os sintomas característicos de hifalomicose descritos por VIOLETTA et al. (1989).

A partir da segunda semana, o animal apresentava-se letárgico e com pequena desorientação; as ulcerações da região do focinho e cabeça aumentaram a ponto de poder-se observar uma pequena secção do condrocrânio. No final da segunda semana, o espécime morreu, com aproximadamente $2 / 3$ do focinho degenerado e região ventral apresentando hemorragias.

Apesar dos sintomas terem sido identificados com clareza, realizaram-se novamente culturas para a identificação do fungo, pois de acordo com a descrição de LEIBoviTZ \& LEIBovitz (1985b), os sintomas são muito parecidos com a dermatite viral, em Mustelus canis.

\section{DISCUSSÃO}

Infecções causadas por Fusarium solani, já foram descritas em tubarões, tartarugas, salmões, camarões e até mesmo em seres humanos (RIPPON 1988). São fungos deuteromicéticos, amplamente distribuídos na natureza e freqüentemente atuam como contaminantes de meios bacteriológicos (EMMONS et al. 1970).

O processo de infecção até a morte do espécime de Mustelus schmitti em cativeiro, foi muito rápido em relação a trabalhos realizados com tubarões-martelo, que desenvolveram a doença após três meses de sua captura (MuHvicH et al. 1989; VioletTA et al. 1989). MCLAUGHLin \& ZAHL (1966) e LeIBovitz \& LEIBOvitZ (1985a), atribuem a diferença no tempo de vida de espécies diferentes com a mesma doença, como sendo, a diferença existente entre os sistemas imunológicos das mesmas. 

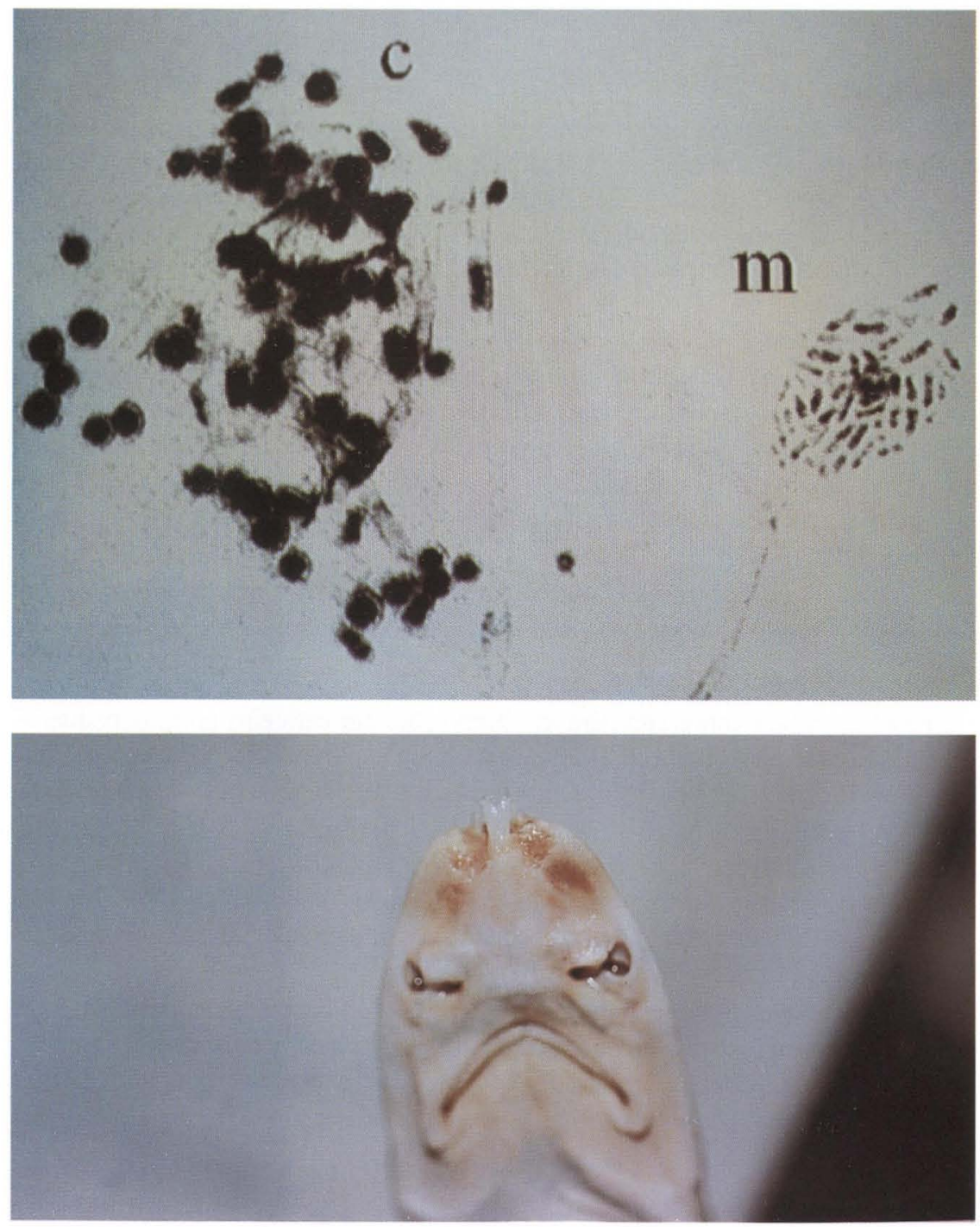

Figs 2-3. (2) Fusarium solani, hifa segmentada com clamidospóros (c) e macroconídias (m) (escala $=0,05 \mathrm{~mm}) ;(3)$ estágio final de desenvolvimento da hifalomicose, observação de necrose e parte do condrocrânio em Mustelus schimitti.

As ulcerações apresentadas nos estágios finais da infecção são respostas secundárias à ação de parasitas, vírus, algas ou fungos, e estão bem descritas nos trabalhos de KHAN (1972), BENZ (1980), BIRD (1981), CHEUNG et al. (1982), SAKANARI \& MOSER (1985) e SCHÄPERCLAUS (1992).

O resultado obtido na verificação da ocorrência de parasitas internos era previsto. As espécies costeiras e de pequeno porte, apresentam poucos registros de infecções parasitárias, devido à sua fisiologia, que é bem diferenciada dos tubarões 
pelágicos e de grande porte, os quais possuem inúmeros registros de endoparasitose (BENZ 1980; BIRD 1981; STOSKOPF 1993).

É incerto o motivo pelo qual estes tubarões adquirem esta patologia. A teoria mais conceituada indica como foco da infecção, escoriações na região da cabeça devido à tentativa de pesca ou durante a captura de seu alimento (MUHVICH et al. 1989; VioletTA et al. 1989). Esses trabalhos sugerem que, populações de tubarões em ambiente natural, podem sofrer impactos devido à grandes infestações de parasitas, que em muitos casos possuem ciclo de vida rápido e fácil transmissão (KHAN 1972).

AGRADECIMENTOS. Aos pescadores Francisco Gomes e Márcio Silva pela captura do material utilizado neste trabalho. Ao biólogo Alexandre M. França pelo auxilio na identificação da espécie de fungo e à professora Isadora Villela pela correção e indicações ortográficas.

\section{REFERÊNCIAS BIBLIOGRÁFICAS}

BENZ, G.W. 1980. Tissue proliferation associated with Nemeis lamma Risso, 1826 (Copepoda, Eudactylinidae) infestations on the gill filaments of shortfin makos (Isurus oxyrinchus). Jour. Fish Dis. 3: 443-446.

BIRD, P. 1981. The occurrence of Cirolana borealis (Isopoda) in the hearts of sharks from Atlantic coastal waters of Florida. Fish. Bull. 79: 376-383.

Cheung, P.J. \& R.F. NigRELli. 1983. Dermophthiriordes pristidis n.gen., n.sp. (Microbothriidae) from the skin and Neoheterocotyle ruggierii n.sp. (Monocotylidae) from the gills of the smalltooth sawfish, Pristis pectinata. Trans. Amer. Microsc. Soc. 102 (4): 366-370.

CheunG, P.J.; R.F. Nigrelli; G.D. Ruggieri \& A. Cilia. 1982. Treatment of skin lesions in captive lemon sharks, Negaprion brevirostris (Poey), caused by monogeneans (Dermophthirius sp.). Jour. Fish Dis. 5: 167-170.

Compagno, L.J.V. 1984. FAO species catalogue. 4. Sharks of the world. An annotated and illustrated catalogue of sharks species known to date. 2. Carcharhiniformes. FAO Fish. Synop. 4 (125): 424-425.

EIRAS, J.C. 1994. Elementos de Ictioparasitologia. Porto, Fund. Eng. António de Almeida, 339p.

EMmons, C.W.; C.H. BINFORd \& J.P. UTZ. 1970. Medical Mycology. Filadélfia, Lea $\&$ Febiger, $2^{\text {nd }}$ ed., $445 p$.

Figueiredo, J.L. 1977. Manual de peixes marinhos do sudeste do Brasil. I. Introdução. Cações, raias e quimeras. São Paulo, Museu de Zoologia, Universidade de São Paulo, 104p.

GonZALEZ, M.M.B. 1995. Maintenance of nurse sharks in captivity. Abstracts XI American Elasmobranch Society Meeting, Alberta, p.110.

KHAN, R.A. 1972. Taxonomy, prevalence, and experimental transmission of a protozoan parasite, Trichodina oviducti Polynansky (Ciliata: Peritrichida). Jour. Parasitol. 58: 680-685.

LEIBOVITZ, L. \& S.S. LEIBOVITZ. 1985a. A coccolithophorid algal dermatitis of the spiny dogfish, Squalus acanthias. Jour. Fish Dis. 8: 351-358.

. 1985b. A viral dermatitis of the smooth dogfish, Mustelus canis (Mitchill). 
Jour. Fish Dis. 8: 273-279.

McLaughin, J.A. \& O. Zahl. 1966. Endozoic algae. In: S.M. Henry (Ed.)

Symbiosis. Londres, Association of Microorganisms, Plants and Marine Organisms Academic Press, Vol. 1, 325p.

MiCHAEL, S.W. 1993. Reef Sharks \& Rays of the World: A guide to their identification, behavior, and ecology. Monterey, Califórnia, Sea Challengers, $107 \mathrm{p}$.

MoORE-LANDERCKER, E. 1972. Fundamentals of the fungi. Englewood Cliffs, Prentice-Hall, 342p.

Muhvich, A.G.; R. Reimschuessel; M.M. Lipsky \& R.O. Bennett. 1989. Fusarium solani isolated from newborn bonnethead sharks, Sphyrna tiburo. Jour. Fish Dis. 12 (1): 57-62.

RIPPON, J.W. 1988. Medical Mycology. Philadelphia, W.B. Saunders, $3^{\text {rd }}$ ed.

SAKANARI, J. \& M. MOSER. 1985. Infectivity of, and laboratory infection with, an elasmobranch cestode, Lacistorynchus tenuis (Van Beneden, 1858). Jour. Parasitol. 7 (16): 788-791.

SCHÄPERCLAUS, W. 1992. Fish Diseases. Roterdam, A.A. Balkema, $5^{\text {th }}$ ed., 1398p. Stoskopf, M.K. 1993. Fish Medicine. Filadélfia, W.B. Saunders Company, 882p. VIOLETTA, G.C.; L.M. DALTON \& R. CRAWLEY. 1989. A case history of Fusarium sp. in a captive population of bonnethead sharks, Sphyrna tiburo. IAAAM Conf. Proceed. 20: 64.

WiLliams JR., E.H. 1982. Leeches of some marine fishes from Puerto Rico and adjacent regions. Proc. Helminthol. Soc. Wash. 49: 135-144.

Recebido em 31.X.1997; aceito em 17.III.1999. 